\title{
Ischemia signalling to Alzheimer-related genes
}

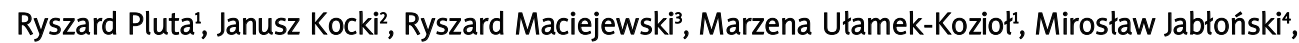 \\ Anna Bogucka-Kocka ${ }^{5}$, Stanisław J. Czuczwar, \\ 'Laboratory of Ischemic and Neurodegenerative Brain Research, Mossakowski Medical Research Centre, Polish Academy of Sciences, \\ Warsaw, Poland, ${ }^{2}$ Department of Clinical Genetics, Lublin Medical University, Lublin, Poland, ${ }^{3}$ Department of Human Anatomy, Lublin \\ Medical University, Lublin, Poland, ${ }^{4}$ Department of Orthopaedics and Rehabilitation, Lublin Medical University, Lublin, Poland, \\ ${ }^{5}$ Department of Pharmaceutical Botany, Lublin Medical University, Lublin, Poland, ${ }^{6}$ Department of Pathophysiology, Lublin Medical \\ University, Lublin, Poland, 'Department of Physiopathology, Institute of Rural Medicine, Lublin, Poland
}

\begin{abstract}
In this paper we review the hard-earned data, which present ischemic induction of amyloid precursor protein, presenilins, apolipoproteins and secretases genes, playing key roles in $\beta$-amyloid peptide generation. Presented data are strongly supporting a hypothesis that brain ischemia may be involved in the aetiology of sporadic Alzheimer's disease. Potential contribution and impact of ischemically activated genes on the development of sporadic Alzheimer's disease remain to be established at both genetic and functional levels. The identification of the genes involved in sporadic Alzheimer's disease induced by ischemia will enable to further define the events leading to Alzheimer's disease-related abnormalities. Additionally, knowledge gained from the reviewed studies should facilitate the elaboration of effective treatment and/or prevention of sporadic Alzheimer's disease.
\end{abstract}

Key words: brain ischemia, postischemic dementia, Alzheimer's genes, amyloid precursor protein, presenilins, apolipoproteins, secretases.

\section{Introduction}

Alzheimer's disease is the most widespread form of progressive and irreversible dementia in the mature population and accounts for more than $30-50 \%$ of cases aged 80-90 and over $[34,46]$. Neuropathologically, the disorder is characterized by neuronal death, intraand extracellular amyloid deposits and neurofibrillary tangles formation in neurons located in specific brain fields like e.g. hippocampus [3]. Factors that modify nutri- tion of brain are among the most consistently identified etiological triggers in the development of the disease [51]. Since the neurovessels are the key site for nutrient and waste products exchange like $\beta$-amyloid peptide between the brain tissue and systemic blood, events that disturb focally or completely brain circulation are likely to be the major culprit during the pathogenesis of sporadic Alzheimer's disease.

Deoxyribonucleic acid (DNA) is a special molecule present in the nucleus of each organism and also brain 
cells, which controls the growth and development of the human and animal being as genes. DNA controls the processes of learning and maturation that turn the young brain into an adult brain. Once maturity is reached, DNA controls the metabolic processes that maintain the brain in its homoeostatic balance with some physiological correction during ageing. It is also possible that DNA may hold a darker secret. It may hold the codes for the neurodegeneration of the brain with age [61], for loss of memory and intelligence and for the clinical syndrome termed dementia $[4,41,77]$. The neuropathological changes of some proteins seen in brain tissue from demented patients (e.g. widespread $\beta$-amyloid peptide deposition as diffuse and senile plaques and tau protein pathology as neurofibrillary tangles) may be a reflection of this dark and secret information in specific brain genes $[3,4,56,57]$. For example, tau hyperphosphorylation and amyloid appear to be the neuropathological proteins most closely linked to the cognitive decline in Alzheimer's disease [21].

Current investigations have demonstrated a close link between sporadic Alzheimer's disease and ischemic brain episodes $[6,43,44,47,50,53,63]$. Additionally, earlier epidemiological studies noted that brain ischemia increased the incidence of sporadic Alzheimer's disease [15] and neurovascular risk factors for brain ischemia also raised the risk of sporadic Alzheimer's disease [58]. Clinical investigations revealed that neurovascular factors could aggravate the progression of Alzheimer's disease $[33,35]$. The occurrence of different parts of amyloid precursor protein and phosphorylated tau protein found in neurofibrillary tangles in ischemic brains strongly suggests a close association between brain ischemia and sporadic Alzheimer's disease [26,36, $43,44,47,49,53,56,71,73]$. Neuropathological post mortem examinations of Alzheimer's disease brains have shown that $30 \%$ of patients show evidence of brain infarction $[34,46]$ and those cases with both Alzheimer's disease and brain ischemia present more severe cognitive impairment than those without brain infarction [66]. A recent study has found that brain ischemia in hippocampus aggravates cognitive impairment of Alzheimer's disease rats by promoting $\beta$-amyloid peptide generation and deposition, neuronal death [49] and pathological phosphorylation of tau protein in ischemic hippocampus [71], finally underpinning the idea that enhanced inflammatory reactions [62] might be responsible for brain ischemia induced as vicious cycle aggravation of cognitive impairment in Alzheimer's disease rats [34].
In consequence, further experimental studies to clarify the triggering effect of brain ischemia on Alzheimer's disease development will not only lead to re-evaluation of the neuropathogenesis of Alzheimer's disease but may also provide key data for the prevention and therapy of Alzheimer's disease. Altogether, it is hypothesized that the brain ischemia could be the main cause of sporadic Alzheimer's disease. Therefore, it is of consequence to study the effects of ischemic brain episodes on Alzheimer's disease formation through animal models for understanding of the neuropathogenesis of sporadic Alzheimer's disease. In the face of new interesting findings, in this review we will try to put together all available information from a genetic point of view. It is hoped that new findings will give some insights on complex interaction between ischemic signalling to Alzheimer-associated genes and $\beta$-amyloid peptide generation in the progressing injury of the ischemic brain to dementia with Alzheimer phenotype.

\section{Induction of Alzheimer-associated genes following experimental brain ischemia \\ Amyloid precursor protein}

Amyloid precursor protein is a member of a family of conserved type 1 membrane proteins, which in mammals includes amyloid precursor protein-like protein 1 and amyloid precursor protein-like protein 2 . Although its function remains uncertain, putative physiological roles in trafficking, neurotrophic signalling, cell adhesion and cell signalling have been proposed. After amyloid precursor protein is synthesized, the mature glycosylated form of amyloid precursor protein in the trans-Golgi network is delivered to the plasma membrane, where it is fairly rapidly turned over by either of two processes: non-amyloidogenic and amyloidogenic. $\beta$-amyloid peptide is derived from the larger parent transmembrane molecule amyloid precursor protein during the amyloidogenic pathway. The gene coding for amyloid precursor protein has been identified on chromosome 21. Amyloid precursor protein mRNA increased over $200-\%$ and $150-\%$ in the penumbra and core ischemic parts, respectively, on the fourth day after focal brain ischemia and remained high through the seventh day of the ischemic insult. This study suggests that the focal brain ischemic insult enhances amyloid precursor protein mRNA expression and may contribute to the progression of cognitive impairment after ischemic injury [65]. After focal ischemia, the Kunitz protease inhibitor-bearing isoforms 
were increased, whereas amyloid precursor protein 695 that lacks Kunitz protease inhibitor domain was decreased. These results show that focal ischemia alters Kunitz protease inhibitor-amyloid precursor protein/ amyloid precursor protein 695 ratios in cerebral cortex and this shift in amyloid precursor protein isoforms could be related to neurodegeneration and/or activation of astrocytes during the ischemic process [27].

In persistent focal ischemia, amyloid precursor protein mRNA species that contain a Kunitz-type protease inhibitor domain were induced in the rat cortex from 1 to 21 days after the injury with maximum at 4 days, while total amounts of amyloid precursor protein mRNA did not change. These results suggest a selective role of amyloid precursor protein species that contain the Kunitz protease inhibitor domain in focal brain ischemia [1]. At 7 days postischemia, amyloid precursor protein 770 and amyloid precursor protein 751 mRNAs were induced in the infarct core and in a thin perifocal zone [30].

Brain samples from ischemic core and penumbra of cortex at one hour and 1 day following focal ischemia with ovariectomy were investigated for amyloid precursor protein mRNA. At one hour after ischemia, rats exhibited a significant increase in amyloid precursor protein mRNA in the penumbra and core. Estrogen treatment reduced the amyloid precursor protein mRNA over-expression in these two areas [64]. These results demonstrate that estrogen may have an important role in reducing the over-expression of amyloid precursor protein mRNA following transient focal ischemia. Thus, these studies suggest a profound effect of estrogen on brain that may be able to interrupt a vicious cycle of ischemia and neurodegeneration [64].

\section{Presenilins}

The protein products of the genes on chromosomes 14 and 1 were subsequently termed presenilin 1 and presenilin 2, respectively. Information regarding the genetic factors and environmental conditions that influence presenilins gene expression is essential for the elucidation of its pathophysiological role in Alzheimer's disease. In one paper, the changes of presenilin $1 \mathrm{mRNA}$ expression in the gerbil hippocampus following complete brain ischemia were studied [67]. After ischemia, the selective induction of presenilin 1 gene in neurons of CA3 and dentate gyrus was observed, which might be related to the resistant areas after ischemia. In this investigation, presenilin 1 mRNA was induced at 1 day postischemia and reached the greatest levels at day 3 in presented regions. These observations suggest that the expression of presenilin 1 mRNA may be associated with some response of nerve cells injured by ischemic insult. In another study, the induction of mRNA for presenilins was examined in the rat hippocampus, cortex, striatum and cerebellum in an experimental model of transient focal brain ischemia [40]. The levels of presenilins mRNA exhibited the maximal expression in the hippocampus and cortex regions of plaque development in Alzheimer's disease while the presenilin 1 and 2 genes content in cerebellum and striatum, regions unaffected by Alzheimer's disease, presented generally no significant increase. The greatest expression for presenilins mRNA was observed in the cortex. Genes for presenilins in the hippocampus and striatum show a pattern of expression similar to that seen in the cortex but with smaller intensities. Generally, the expressions were larger on the contralateral side to the focal ischemic injury. This difference may reflect a loss of brain cells expressing presenilin genes on the ipsilateral side.

\section{Apolipoproteins}

The apolipoprotein $\mathrm{E}$ gene is on chromosome 19 . Since $\beta$-amyloid peptide binds with high affinity to apolipoprotein $\mathrm{E}$ it has been suggested that apolipoprotein $\mathrm{E}$ may promote formation of $\beta$-amyloid peptide fibrils by acting as a 'pathological chaperone' [74]. In an experimental study on gerbil, there was an increase in astrocytic apolipoprotein E mRNA with the levels being the highest 7 days postischemia. This suggests that neuronal injury or insult results in the induction of certain genes in the surrounding reactive astrocytes and these proteins may contribute to post injury amyloidogenesis [2]. Apolipoprotein E mRNA expression in glial cells but not in neurons was seen in ischemic penumbra with a peak at 21 days. In core, marked apolipoprotein $\mathrm{E}$ mRNA expression was observed in macrophages [23]. Apolipoprotein E immunoreactivity was recognized in astrocytes and neurons 3-14 days after transient focal cerebral ischemia. Apolipoprotein $\mathrm{E}$ was also detected in macrophages in the ischemic core. In contrast, apolipoprotein E mRNA was expressed in astrocytes and macrophages but not in neurons. These results suggest that neuronal apolipoprotein $E$ was not synthesized in neurons but derived from astrocytes [39]. Recent findings support this observation that astroglial cells regulate apolipoprotein E expression in neurons [16] 
Some data present an increased expression in astrocytes of apolipoprotein J which provides neuroprotection against brain ischemia as an antistress protein chaperone [72]. Increased expression of clusterin mRNA was noted in permanent focal cerebral ischemia in the mouse. Clusterin mRNA was located in the perifocal area. Reactive astrocytes within the cortex were found to be strongly immunoreactive for clusterin. It was concluded that the local expression of apolipoprotein J mRNA might contribute to the inflammation, representing an important process in secondary injury mechanisms after focal and global brain ischemia $[62,68]$. The severe ischemic insult leads primarily to necrotic neuronal death and shows very little, if any, clusterin mRNA. However, following the moderate insult, there was a dramatic time-dependent accumulation of clusterin in neurons of the CA1 and CA2 sector in the hippocampus and cortical layers 3-5 regions undergoing delayed neuronal death. Clusterin mRNA expression, in contrast to neuronal protein accumulation, appeared to be glial in origin with increases in mRNA in and around the hippocampus fissure and only a weak signal over the CA1 and CA2 pyramidal cell layer. These results support the theory that clusterin is synthesized in the astrocytes, secreted and then taken up by dying neurons [39]. Clusterin was accumulating in neurons destined to die by programmed cell death. However, clusterin expression suggests that clusterin production was a result of the selective delayed neuronal death rather than being involved in the neurochemical cascade of events that cause it [69].

\section{$\alpha$-, $\beta$ - and $\gamma$-secretases}

The amyloid precursor protein is cleaved by $\alpha$-secretase and it is a non-amyloidogenic pathway. $\alpha$-Secretase displays characteristics of certain membrane-tethered metalloproteases. Further, $\alpha$-secretase activity has both constitutive and inducible components. The constitutive activity has not been identified yet, but inducible $\alpha$-secretase activity seems to be under the control of protein kinase $C$. Two members of a disintegrin and metalloprotease (ADAM) family, tumour necrosis factor- $\alpha$ converting enzyme (TACE or ADAM-17) and ADAM-10 also seem to process the amyloid precursor protein in an $\alpha$-secretase-like manner. Experimental brain ischemia results in the downregulation of mRNA of $\alpha$-secretase and decreases its activity $[38,76]$. In the second pathway, amyloidogenic precursor is cleaved by $\beta$-and $\gamma$-secretases to form soluble $\beta$-amyloid pep- tide. In 1999, $\beta$-secretase was identified as a protein with homology to the pepsin family of aspartyl proteases. The gene for $\beta$-secretase is located on chromosome 11 . $\beta$-Secretase mRNA is highly expressed in the brain and it is also found in a variety of human tissues. The intracellular localization of $\beta$-secretase protein is expressed primarily in the Golgi apparatus and in endosomes, whereas a small amount of it can be detected in endoplasmic reticulum, lysosomes and the plasma membrane. Zhang et al. [80] found that the human and animal $\beta$-secretase gene promoters contain the hypoxia inducible factor 1 binding sites and the hypoxia responsive element site is physiologically functional in the transcriptional regulation of $\beta$-secretase gene expression in vitro and in vivo. The production of $\beta$-amyloid peptide increases in the brain after ischemia, which impairs the memory [76]. Recent data have shown that experimental ischemic brain injury stimulates the expression, production and activity of Alzheimer's disease $\beta$-secretase in animal brain parenchyma $[7,12,13,70]$. Another study showed for the first time the alteration in mRNA expression of three amyloid precursor protein metabolism-related genes: $\beta$-secretase (BACE1), cathepsin B and glutaminyl cyclase mRNA, whose expression increased in the hippocampus and cortex quickly after ischemia-recirculation [78]. In the following month, the BACE1 mRNA level dropped subsequently but was still above the control level during the whole period of observation. Another result has shown that full-length presenilin interacts with immature $\beta$-secretase. This observation suggests that presenilin regulates $\beta$-secretase activity via direct interaction and facilitated trafficking of $\beta$-secretase to different compartments of cells [18]. Additionally, presenilin is involved in the processing of amyloid precursor protein to produce $\beta$-amyloid peptide through the $\gamma$-secretase complex [75]. $\gamma$-secretase has pharmacological characteristics of an aspartyl protease and is a high molecular weight complex that consists of at least four components: presenilin-1 (PEN-1), nicastrin (Nct), anterior pharynx-defective-1 (APH-1) and presenilin enhancer-2 (PEN-2). It is known that isolated autophagic vacuoles contain the highest $\gamma$-secretase activity and ischemia can activate macroautophagy (autophagy) in the brain, resulting in the increase of autophagic vacuoles. Therefore, we propose that ischemia may accelerate $\beta$-amyloid peptide production through activating autophagy. Presenilin, which is expressed in the ischemic brain $[40,67]$, is involved in ischemic $\beta$-amyloid peptide generation by $\gamma$-secretase complex [54]. These findings will help understand the 
gradual creepy postischemic damage in ischemic neurons structures, delayed $\beta$-amyloid peptide deposition and long-term neurovascular pathogenesis of Alzheimertype [49].

\section{Intracellular C-terminal of amyloid precursor protein domain (AICD) generation}

A primary trigger in brain ischemia, which initiates amyloid precursor protein cleavage is ischemic process. The first proteolysis is performed by either $\alpha$ - or $\beta$-secretase that produce large soluble $N$-terminal domains such as: SAPP $\alpha$ or SAPP 3 . These fragments are released into the extracellular space. Remaining $C$-terminal fragments are bound with a membrane and called, $C$-terminal fragment 83 or 99 (CTF83/CTF $\alpha$ or CTF99/CTF $\beta$ ), respectively. The second proteolysis occurs in the intramembrane area by $\gamma$-secretase, which, depending on where the first proteolysis was made, finally releases either the $\beta$-amyloid peptide or $\mathrm{p} 3$ fragment. This action seems to be largely nonselective, occurring in at least 3 different sites of the amyloid precursor protein like V636, A638 and L645 ( $\varepsilon$-cleavage site) $[60,79]$. The final main products are $\beta$-amyloid peptide 40 or 42 and an intracellular 50 aa $C$-terminal of amyloid precursor protein domain $(5 \mathrm{kDa})$ (AICD) [42]. AICD is extremely labile and can be further degraded by the insulin degrading enzyme or proteasome. AICD, with binding proteins initiating a signal cascade, subsequently migrates to the cell nucleus to become a component of a transcriptional complex. The adaptor protein FE65 rescues the AICD from rapid degradation. Amyloid precursor protein intracellular domain may well control transcription of genes by shaping a transcriptionally dynamic complex with the adaptor protein Fe 65 and the histone acetyltransferase Tip60 [11]. The equilibrium between non-amyloidogenic and amyloidogenic processes is vital, since very small alterations in this fine balance can begin rapid mechanisms leading to the generation and deposition of $\beta$-amyloid peptide in brains of Alzheimer's disease sufferers.

\section{Functional consequences following experimental brain ischemia}

In addition to pathological ischemic alterations, neurobehavioral functional changes have been observed, too $[8,28,52]$. Brain ischemia does not result in long-lasting neurological deficits in animals [8]. Spontaneous par- tial or complete recovery of the sensorimotor function has been observed following ischemic brain lesions $[28,55,77]$. After brain ischemia, a locomotor hyperactivity has been noted during 7 days $[24,31]$ as in Alzheimer's disease patients. The hyperactivity was associated with a neuronal loss in hippocampus [31]. Longer ischemia and longer locomotor hyperactivity, which is positive, correlated with increased hippocampal neuronal changes/deaths $[8,49]$. Following brain ischemia, an impairment in habituation up to 6 months was observed, as revealed by an increase in the exploration time [10,37]. Ischemic brain injury results in reference and working memory deficits $[14,28,29]$. Moreover, ischemic brain injury in experimental animals leads to progression of spatial memory for 1 year and more $[9,25,28]$. Cognitive impairment progression has been presented consistently during recirculation time $[25,28,59]$. Moreover, data from repetitive brain ischemia in gerbils have shown persistent locomotor hyperactivity, reduced anxiety and severe cognitive deficits [20]. These abnormalities were connected with significant brain atrophy $[19,44,45,48]$, associated with a diffuse neuronal loss in the brain cortex, caudate nucleus and in CA1 sector of hippocampus $[20,48,49]$ and in the amygdala and perirhinal cortex [5]. Alertness and sensorimotor capacities are affected for 1-2 days, whereas the deficits in learning and memory seem to be rather long-lasting [28]. Taken together, supporting evidence from both experimental and clinical studies indicating that the progressive cognitive activities decline, could not be explained only by the direct contribution of the primary ischemic brain injury, but rather a progressive consequence of the additive effects of the ischemic lesions, Alzheimer's factors and aging [22, $32,52,55]$. These data suggest that focal ischemia enhances amyloid precursor protein mRNA expression, which may contribute to the progression of cognitive impairment in postischemic injury $[64,65]$. Finally, the production of $\beta$-amyloid peptide in brain after ischemia increases and impairs the memory [76]. Abnormal $\alpha$-synuclein deposition might completely disrupt synaptic activity, resulting in cognitive disturbance [17]. The functional alterations were shown within the areas of selective vulnerability to ischemia neurons and they precede neurodegeneration. Additionally, other regions of brain, which are devoid of ischemic neuronal injury, display functional abnormalities. These changes seem to be mainly due to synaptic changes because of connections of neuronal cells within sectors with ischemically damaged and dead neurons [17]. 


\section{Conclusions}

The typical elements of Alzheimer's disease pathology in ischemic brain are abnormal induction of Alzheimer's disease-associated genes and proteins, various kinds of amyloid plaques, and neuronal death with inflammation in specific brain fields as hippocampus with the final development of dementia. To date causes of plaques have been taken as heterogeneous and neuronal death as a consequence of neurotoxic futures of $\beta$-amyloid peptide. New data are suggesting that brain ischemia triggers parallel induction of Alzheimer type genes and neuronal death with subsequent plaques development and detected hippocampus and brain atrophy $[19,44,45,48]$, which is important in final dementia formation [28]. The data on Alzheimer's genotype and phenotype in brain ischemia underpin directly the ischemic hypothesis of Alzheimer's disease aetiology. In summary, we presented good ischemic models for the investigation of Alzheimer's disease. By use of brain ischemia models, we may elucidate the neuropathology of Alzheimer's disease. Present knowledge regarding the induction of genes, neuropathophysiology and neuropathology of brain ischemia and Alzheimer's disease indicates that the same processes contribute to neuronal death, amyloid accumulation, tau protein hyperphosphorylation and brain parenchyma disintegration with full-blown dementia $[6,50,71]$.

\section{Acknowledgements}

This study was supported in part by funds from: the Mossakowski Medical Research Centre, Polish Academy of Sciences (T4, RP), Lublin Medical University (DS475/11, SJC), and the Polish Ministry of Science and Higher Education (project N N312233938 ABK). The paper was developed using the equipment purchased within the project 'The equipment of innovative laboratories doing research on new medicines used in the therapy of civilization and neoplastic diseases' within the Operational Program Development of Eastern Poland 2007-2013, Priority Axis I Modern Economy, Operations 1.3 Innovation Promotion.

\section{References}

1. Abe K, Tanzi RE, Kogure K. Selective induction of Kunitz-type protease inhibitor domain-containing amyloid precursor protein mRNA after persistent focal ischemia in rat cerebral cortex. Neurosci Lett 1991; 125: 172-174.

2. Ali SM, Dunn E, Oostveen JA, Hall ED, Carter DB. Induction of apolipoprotein E mRNA in the hippocampus of the gerbil after transient global ischemia. Mol Brain Res 1996; 38: 37-44.
3. Armstrong RA. Spatial patterns of $\beta$-amyloid $(A \beta)$ deposits in familial and sporadic Alzheimer's disease. Folia Neuropathol 2011; 49: 153-161.

4. Arshavsky YI. Why Alzheimer's disease starts with a memory impairment: Neurophysiological insight. J Alzheimer's Dis 2010; 20 : 5-16.

5. Barra de la Tremblaye P, Plamondon H. Impaired conditioned emotional response and object recognition are concomitant to neuronal damage in the amygdale and perirhinal cortex in middleaged ischemic rats. Behav Brain Res 2011; 219: 227-233.

6. Bell R, Zlokovic B. Neurovascular mechanisms and blood-brain barrier disorders in Alzheimer's disease. Acta Neuropathol 2009; 118: 103-113.

7. Blasko I, Beer R, Bigl M, Apelt J, Franz G, Rudzki D, Ransmayr G, Kampfl A, Schliebs R. Experimental traumatic brain injury in rats stimulates the expression, production and activity of Alzheimer's disease $\beta$-secretase (BACE-1). J Neural Transm 2004; 111: 523-536.

8. Block F. Global ischemia and behavioural deficits. Prog Neurobiol 1999; 58: 279-295.

9. Block F, Schwarz M. Global ischemic neuronal damage relates to behavioural deficits: a pharmacological approach. Neuroscience 1998; 82: 791-803.

10. Colbourne F, Corbett D. Delayed postischemic hypothermia: a six month survival study using behavioral and histological assessments of neuroprotection. J Neurosci 1995; 15: 7250-7260.

11. Cao X, Sudhof TC. A transcriptionally active complex of APP with Fe65 and histone acetyltransferase Tip60. Science 2001; 293: 115-120.

12. Chen XH, Siman R, Iwata A, Meaney DF, Trojanowski JQ, Smith DH. Long-term accumulation of amyloid- $\beta, \beta$-secretase, presenilin-1, and caspase- 3 in damaged axons following brain trauma. Am J Pathol 2004; 165: 357-371.

13. Chuang CM, Hsieh CL, Lin HY, Lin JG. Panax Notoginseng Burk attenuates impairment of learning and memory functions and increases ED1, BDNF and beta-secretase immunoreactive cells in chronic stage ischemia-reperfusion injured rats. Am J Chin Med 2008; 36 : 685-693.

14. Davis HP, Tribuna J, Pulsinelli WA, Volpe BT. Reference and working memory of rats following hippocampal damage induced by transient forebrain ischemia. Physiol Behav 1986; 37: 387-392.

15. Esiri MM, Nagy Z, Smith MZ, Barnetson I, Smith AD. Cerebrovascular disease and threshold for dementia in the early stages of Alzheimer's disease. Lancet 1999; 354: 919-920.

16. Harris FM, Tesseur I, Brecht WJ, Xu O, Mullendorff K, Chang S, WyssCoray T, Mahley RW, Huang Y. Asroglial regulation of apolipoprotein E expression in neuronal cells. Implications for Alzheimer's disease. J Biol Chem 2004; 279: 3862-3868.

17. Hashimoto M, Masliah E. Alpha-synuclein in Lewy body disease and Alzheimer's disease. Brain Pathol 1999; 9: 707-720.

18. Hebert SS, Bourdages V, Godin C, Ferland M, Carreau M, Levesque G. Presenilin-1 interacts directly with the beta-site amyloid protein precursor-cleaving enzyme (BACE1). Neurobiol Dis 2003; 13: 238-245.

19. Hossmann KA, Schmidt-Kastner R, Grosse Ophoff B. Recovery of integrative central nervous function after one hour global cerebrocirculatory arrest in normothermic cat. J Neurol Sci 1987; 77 : 305-320 
20. Ishibashi S, Kuroiwa T, LiYuan S, Katsumata N, Li S, Endo S, Mizu sawa H. Long-term cognitive and neuropsychological symptoms after global cerebral ischemia in Mongolian gerbils. Acta Neurochir (Suppl) 2006; 96: 299-302.

21. Jack CRJr, Lowe VJ, Weigand SD, Wiste HJ, Senjem ML, Knopman DS, Shiung MM, Gunter JL, Boeve BF, Kemp BJ, Weiner M, Petersen RC; Alzheimer's Disease Neuroimaging Initiative. Serial PIB and $M R I$ in normal, mild cognitive impairment and Alzheimer's disease: implications for sequence of pathological events in Alzheimer's disease. Brain 2009; 132: 1355-1365.

22. Jellinger KA. The enigma of vascular cognitive disorder and vascular dementia. Acta Neuropathol 2007; 113: 349-388.

23. Kamada H, Sato K, Zhang WR, Omori N, Nagano I, Shoji M, Abe K. Spatiotemporal changes of apolipoprotein E immunoreactivity and apolipoprotein E mRNA expression after transient middle cerebra artery occlusion in rat brain. J Neurosci Res 2003; 73: 545-556.

24. Karasawa Y, Araki H, Otomo S. Changes in locomotor activity and passive avoidance task performance induced by cerebral ischemia in mongolian gerbils. Stroke 1994; 25: 645-650.

25. Karhunen H, Pitkanen A, Virtanen T, Gureviciene I, Pussinen R, Ylinen A, Sivenius J, Nissinen J, Jolkkonen J. Long-term functional consequences of transient occlusion of the middle cerebral artery in rats: a 1-year follow-up of the development of epileptogenesis and memory impairment in relation to sensorimotor deficits. Epilepsy Res 2003; 54: 1-10.

26. Kato T, Hirano A, Katagiri T, Sasaki H, Yamada S. Neurofibrillary tangle formation in the nucleus basalis of Meynert ipsilateral to a massive cerebral infarct. Ann Neurol 1988; 23: 620-623.

27. Kim HS, Lee SH, Kim SS, Kim YK, Jeong SJ, Ma J, Han DH, Cho BK, Suh YH. Post-ischemic changes in the expression of Alzheimer's APP isoforms in rat cerebral cortex. NeuroReport 1998; 9: 533-537.

28. Kiryk A, Pluta R, Figiel I, Mikosz M, Ułamek M, Niewiadomska G, Jabłoński M, Kaczmarek L. Transient brain ischemia due to cardiac arrest causes irreversible long-lasting cognitive injury. Behav Brain Res 2011; 219: 1-7.

29. Kiyota Y, Miyamoto M, Nagaoka A. Relationship between brain damage and memory impairment in rats exposed to transient forebrain ischemia. Brain Res 1991; 538: 295-302.

30. Koistinaho J, Pyykonen I, Keinanen R, Hokfelt T. Expression of $\beta$-amyloid precursor protein mRNAs following transient focal ischaemia. Neuroreport 1996; 7: 2727-2731.

31. Kuroiwa T, Bonnekoh P, Hossmann KA. Locomotor hyperactivity and hippocampal CA1 injury after transient forebrain ischemia in gerbils. Neurosci Lett 1991; 122: 141-144.

32. Langdon KD, Granter-Button S, Corbett D. Persistent behavioral impairments and neuroinflammation following global ischemia in the rat. Eur J Neurosci 2008; 28: 2310-2318.

33. Li J, Zhang M, Xu ZQ, Gao CY, Fang CQ, Deng J, Yan JC, Wang YJ, Zhou HD. Vascular risk aggravates the progression of Alzheimer's disease in a Chinese cohort. J Alzheimers Dis 2010; 20: 491-500.

34. Li J, Wang YJ, Zhang M, Fang CQ, Zhou HD. Cerebral ischemia aggravates cognitive impairment in a rat model of Alzheimer's disease. Life Sciences 2011; 89: 86-92.

35. Li J, Wang YJ, Zhang M, Xu ZQ, Gao CY, Fang CQ, Yan JC, Zhou HD; Chongqing Ageing Study Group. Vascular risk factors promote conversion from mild cognitive impairment to Alzheimer disease. Neurology 2011; 76: 1485-1491.
36. Maślińska D, Laure-Kamionowska M, Taraszewska A, Deregowski K, Maśliński S. Immunodistribution of amyloid beta protein $(A \beta)$ and advanced glycation end-product receptors (RAGE) in choroid plexus and ependyma of resuscitated patients. Folia Neuropathol 2011; 49: 295-300.

37. Mileson BE, Schwartz RD. The use of locomotor activity as a behavioral screen for neuronal damage following transient forebrain ischemia in gerbils. Neurosci Lett 1991; 128: 71-76.

38. Nalivaeva NN, Fisk L, Kochkina EG, Plesneva SA, Zhuravin IA, Babusikova E, Dobrota D, Turner AJ. Effect of hypoxia/ischemia and hypoxic preconditioning/reperfusion on expression of some amyloid-degrading enzymes. Ann NY Acad Sci 2004; 1035: 21-33.

39. Nishio M, Kohmura E, Yuguchi T, Nakajima Y, Fujinaka T, Akiyama C, Iwata A, Yoshimine T. Neuronal apolipoprotein $E$ is not synthesized in neuron after focal ischemia in rat brain. Neurol Res 2003; 25 : 390-394.

40. Pennypacker KR, Hernandez H, Benkovic S, Morgan DG, Willing AE, Sanberg PR. Induction of presenilins in the rat brain after middle cerebral arterial occlusion. Brain Res Bull 1999; 48: 539-543.

41. Pinkston JB, Alekseeva N, Gonzalez Toledo E. Stroke and dementia. Neurol Res 2009; 31: 824-831

42. Pinnix I, Musunuru U, Tun H, Sridharan A, Golde T, Eckman C, ZianiCherif C, Onstead L Sambamurti K. A novel $\gamma$-secretase assay based on detection of the putative C-terminal fragment- $\gamma$ of amyloid $\beta$ protein precursor. J Biol Chem 2001; 276: 481-487.

43. Pluta R, Kida E, Lossinsky AS, Golabek AA, Mossakowski MJ, Wisniewski HM. Complete cerebral ischemia with short-term survival in rats induced by cardiac arrest. I. Extracellular accumulation of Alzheimer's $\beta$-amyloid protein precursor in the brain. Brain Res 1994; 649: 323-328.

44. Pluta R. The role of apolipoprotein $E$ in the deposition of $\beta$-amyloid peptide during ischemia-reperfusion brain injury. A model of early Alzheimer's disease. Ann NY Acad Sci 2000; 903: 324-334.

45. Pluta R. Astroglial expression of the beta-amyloid in ischemia-reperfusion brain injury. Ann NY Acad Sci 2002; 977: 102-108.

46. Pluta R. Ischemia-reperfusion factors in sporadic Alzheimer's disease. In: Welsh EM (ed.). New Research on Alzheimer's Disease. Nova Science Publishers, Inc., New York 2006; pp. 183-234.

47. Pluta R. Ischemia-reperfusion pathways in Alzheimer's disease. Nova Science Publishers, Inc., New York 2007.

48. Pluta R, Ułamek M, Jabłoński M. Alzheimer's mechanisms in ischemic brain degeneration. Anat Rec 2009; 292: 1863-1881.

49. Pluta R, Januszewski S, Jabłoński M, Ułamek M. Factors in creepy delayed neuronal death in hippocampus following brain ischemiareperfusion injury with long-term survival. Acta Neurochir Suppl 2010; 106: 37-41.

50. Pluta R, Ułamek M, Jabłoński M. Consideration of the ischaemic basis and treatment of Alzheimer's disease. Folia Neuropathol 2010; 48: $11-26$.

51. Pluta R. Unresolved questions concerning etiology of Alzheimer's disease: hypomeatbolism. Nutrition 2011; 27: 1-2.

52. Pluta R, Jolkkonen J, Cuzzocrea S, Pedata F, Cechetto D, Popa-Wagner A. Cognitive impairment with vascular impairment and degeneration. Curr Neurovasc Res 2011; 8: 342-350. 
53. Pluta R, Jabłoński M, Czuczwar SJ. Postischemic dementia with Alzheimer phenotype: selectively vulnerable versus resistant areas of the brain and neurodegeneration versus $\beta$-amyloid peptide. Folia Neuropathol 2012; 50: 101-109.

54. Polavarapu R, An J, Zhang C, Yepes M. Regulated intramembrane proteolysis of the low-density lipoprotein receptor-related protein mediates ischemic cell death. Am J Pathol 2008; 172: 1355-1362.

55. Popa-Wagner A. Alzheimer's disease pathological factors in ischemic aged brain. In: Pluta R (ed.). Ischemia-reperfusion pathways in Alzheimer's disease. Nova Science Publishers, Inc., New York, 2007; pp. 51-84.

56. Qi J, Wu H, Yang Y, Wand D, Chen Y, Gu Y, Liu T. Cerebral ischemia and Alzheimer's disease: The expression of amyloid- $\beta$ and apolipoprotein E in human hippocampus. J Alzheimer's Dis 2007; 12: 335-341.

57. Querfurth HW, LaFerla FM. Alzheimer's disease. N Engl J Med 2010; 362: 329-344.

58. Reitz C, Patel B, Tang MX, Manly J, Mayeux R, Luchsinger JA. Relation between vascular risk factors and neuropsychological test performance among elderly persons with Alzheimer's disease. J Neurol Sci 2007; 257: 194-201.

59. Roof RL, Schielke GP, Ren X, Hall ED. A comparison of longterm functional outcome after 2 middle cerebral artery occlusion models in rats. Stroke 2001; 32: 2648-2657.

60. Sastre M, Steiner H, Fuchs K, Capell A, Multhaup G, Condron MM, Teplow DB, Haass C. Presenilin-dependent gamma-secretase processing of beta-amyloid precursor protein at a site corresponding to the S3 cleavage of Notch. EMBO Rep 2001; 2: 835-841.

61. Saver JL. Time is brain - quantified. Stroke 2006; 37: 263-266.

62. Sekeljic V, Bataveljic D, Stamenkovic S, Ułamek M, Jabłoński M, Radenovic L, Pluta R, Andjus PR. Cellular markers of neuroinflammation and neurogenesis after ischemic brain injury in the long-term survival rat model. Brain Struct Funct 2012; 217: 411-420.

63. Sheng B, Cheng LF, Law CB, Li HL, Yeung KM, Lau KK. Coexisting cerebral infarction in Alzheimer's disease is associated with fast dementia progression: applying the National Institute for Neurological Disorders and Stroke/Association Internationale pour la Recherche et l'Enseignement en Neurosciences Neuroimaging Criteria in Alzheimer's disease with Concomitant Cerebral Infarction. J Am Geriatr Soc 2007; 55: 918-922.

64. Shi J, Panickar KS, Yang SH, Rabbani O, Day AL, Simpkins JW. Estrogen attenuates over-expression of beta-amyloid precursor protein messenger RNA in an animal model of focal ischemia. Brain Res 1998; 810: 87-92.

65. Shi J, Yang SH, Stubley L, Day AL, Simpkins JW. Hypoperfusion induces overexpression of $\beta$-amyloid precursor protein mRNA in a focal ischemic rodent model. Brain Res 2000; 853: 1-4.

66. Snowdon DA, Greiner LH, Mortimer JA, Riley KP, Greiner PA, Markesbery WR. Brain infarction and the clinical expression of Alzheimer disease. The nun study. JAMA 1997; 277: 813-817.

67. Tanimukai H, Imaizumi K, Kudo T, Katayama T, Tsuda M, Takagi T, Tohyama M, Takeda M. Alzheimer-associated presenilin-1 gene is induced in gerbil hippocampus after transient ischemia. Mol Brain Res 1998; 54: 212-218.

68. Van Beek J, Chan P, Bernaudin M, Petit E, MacKenzie ET, Fontaine M. Glial responses, clusterin, and complement in permanent focal cerebral ischemia in the mouse. Glia 2000; 31: 39-50.
69. Walton M, Young D, Sirimanne E, Dodd J, Christie D, Williams C, Gluckman P, Dragunow M. Induction of clusterin in the immature brain following a hypoxic-ischemic injury. Mol Brain Res 1996; 39 : 137-152.

70. Wen Y, Onyewuchi O, Yang S, Liu R, Simpkins JW. Increased betasecretase activity and expression in rats following transient cerebral ischemia. Brain Res 2004; 1009: 1-8.

71. Wen Y, Yang SH, Liu R, Perez EJ, Brun-Ziukemagel AM, Koulen P, Simpkins JW. Cdk5 is involved in NFT-like tauopathy induced by transient cerebral ischemia in female rats. Biochim Biophys Acta 2007; 1772: 473-483.

72. Wiggins AK, Shen PJ, Gundlach AL Delayed, but prolonged increases in astrocytic clusterin (ApoJ) mRNA expression following acute cortical spreading depression in the rat: evidence for a role of clusterin in ischemic tolerance. Mol Brain Res 2003; 114: 20-30.

73. Wiśniewski HM, Maślińska D. Beta-protein immunoreactivity in the human brain after cardiac arrest. Folia Neuropathol 1996; 34: 65-71.

74. Wisniewski T, Frangione B. Apolipoprotein E: a pathological chaperone protein in patients with cerebral and systemic amyloid. Neurosci Lett 1992; 135: 235-238.

75. Wolfe MS, Xia W, Ostaszewski BL, Diehl TS, Kimberly WT, Selkoe DJ. Two transmembrane aspartates in presenilin-1 required for presenilin endoproteolysis and gamma-secretase activity. Nature 1999; 398: 513-517.

76. Yan FL, Zhang J, Guan XN, Hong Z. mRNA expression and activity of ADAM17 in hippocampus after chronic cerebral hypoperfusion: experiment with aged rats. Zhonghua Yi Xue Za Zhi 2007; 87: 2515-2517

77. Yang SH, Simpkins JW. Ischemia-reperfusion promotes tau and beta-amyloid pathology and a progressive cognitive impairment. In: Pluta R (ed.). Ischemia-reperfusion pathways in Alzheimer's disease. Nova Science Publishers, Inc. New York, 2007; pp. 113-138.

78. Ye J, Pi R, Mao X, Chen X, Qin J, Xu S, Liu P. Alterations in mRNA expression of BACE1, cathepsin B, and glutaminyl cyclase in mice ischemic brain. Neuroreport 2009; 20: 1456-1460.

79. Yu C, Kim SH, Ikeuchi T, Xu H, Gasparini L, Wang R, Sisodia SS. Characterization of a presenilin-mediated amyloid precursor protein carboxyl-terminal fragment $\gamma$. Evidence for distinct mechanisms involved in $\gamma$-secretase processing of the APP and Notch1 transmembrane domains. J Biol Chem 2001; 276: 43756-43760.

80. Zhang X, Zhou K, Wang R, Cui J, Lipton SA, Liao FF, Xu H, Zhang YW. Hypoxia-inducible factor $1 \alpha$ (HIF- $1 \alpha)$-mediated hypoxia increases BACE1 expression and $\beta$-amyloid generation. J Biol Chem 2007; 282: 10873-10880. 